Supporting Information

\title{
Modification of Carbon Nitride/Reduced Graphene Oxide van der Waals Heterostructure with Copper Nanoparticles to Improve $\mathrm{CO}_{2}$ Sensitivity
}

\author{
James E. Ellis ${ }^{1}$, Dan C. Sorescu ${ }^{2,3}$, Sean I. Hwang ${ }^{1}$, Seth C. Burkert ${ }^{1}$, David L. White ${ }^{l}$, \\ Hyojeong $\mathrm{Kim}^{1}$, Alexander Star ${ }^{1 *}$
}

1. Department of Chemistry, University of Pittsburgh, Pittsburgh, Pennsylvania 15260, United States

2. United States Department of Energy, National Energy Technology Laboratory, Pittsburgh, Pennsylvania 15236, United States

3. Department of Chemical and Petroleum Engineering, University of Pittsburgh, Pittsburgh, PA 15261, United States

Email: astar@pitt.edu 


\section{Table of Contents}

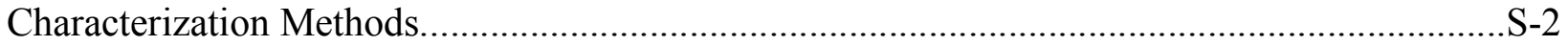

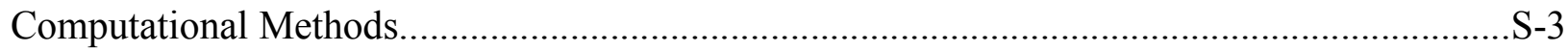

Figure S1. Survey XPS of rGO, CuNP@rGO, and carbon nitride ...............................................5

Figure S2. High-resolution $\mathrm{Cu}_{2 \mathrm{p}}$ and $\mathrm{O}_{1 \mathrm{~s}}$ XPS scans of CuNP@rGO......................................6

Figure S3. PXRD of CuNP@rGO.........................................................................................S-7

Figure S4. Response of carbon nitride/rGO (no $\mathrm{Cu}$ NPs) chemiresistor toward 5 vol\% $\mathrm{CO}_{2} \ldots . . \mathrm{S}-8$

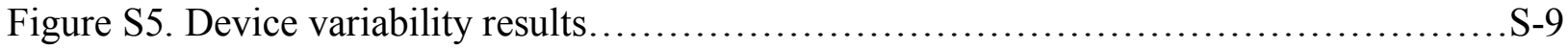

Figure S6. $\mathrm{CO}_{2}$ sensitivity of carbon nitride/CuNP@rGO without UV light..........................S-10

Figure S7. $\mathrm{CO}_{2}$ sensitivity of CuNP-rGO (no carbon nitride) $\ldots \ldots \ldots \ldots \ldots \ldots \ldots \ldots \ldots \ldots . \mathrm{S}-11$

Figure S8. Calculated adsorption energies of $\mathrm{CO}_{2}$ on $\mathrm{Cu} / \mathrm{rGO} /$ carbon nitride................ -12

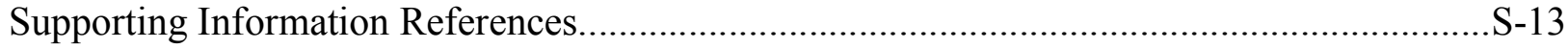

\section{Characterization Methods:}

X-ray photoelectron spectroscopy (XPS): XPS was performed on an ESCALAB 250Xi. Carbon nitride powder samples were placed directly onto copper tape, which were subsequently fixed onto the XPS sample holder. CuNP@rGO and bare rGO samples were dropcast from DMF solution onto aluminum foil and subsequently secured onto the XPS sample holder with copper tape. For the carbon nitride sample, an electron flood gun was run simultaneously with the experiment to allow charge compensation. Survey and valence scans were collected for each sample. Because of surface contamination on the surface of $\mathrm{Cu}$ and $\mathrm{rGO}$, an $\mathrm{Ar}$ ion etching treatment $(3000 \mathrm{eV}, 60$ seconds) was applied before collecting the XPS data.

Ultraviolet photoelectron spectroscopy (UPS): UPS was performed on an ESCALAB 250Xi. The XPS samples (preparation mentioned above) were also used for UPS. The UV source was a HeI emission line $(21.2 \mathrm{eV})$. The band pass energy was $40 \mathrm{eV}$ and $-10 \mathrm{~V}$ sample bias voltage was 
applied. An electron flood gun was used on the carbon nitride sample to allow charge compensation.

\section{Computational Methods}

Interaction of $\mathrm{CO}_{2}$ with different models of $\mathrm{Cu} \mathrm{NP}$ supported on $\mathrm{rGO}(\mathrm{CuNP} @ \mathrm{rGO})$ or at the interface of these systems with a carbon nitride layer have been investigated using first principles DFT calculations in conjunction with periodic slab models. Calculations were performed using Vienna $a b$ initio simulation package $^{\mathrm{S} 1, \mathrm{~S} 2}$ with $\mathrm{PBE}$ exchange correlation functional ${ }^{\mathrm{S} 3}$ and projector augmented wave pseudopotentials. ${ }^{\mathrm{S} 4}$ Grimme's D3 method ${ }^{\mathrm{S} 5}$ has been used to correct for long-range dispersion interactions. The spin contributions have been considered by performing spin-polarized calculations. A cutoff energy of $400 \mathrm{eV}$ was used to expand the plane-wave basis set in optimization calculations. This cutoff energy was increased to $500 \mathrm{eV}$ in analysis of electronic properties. Two sets of slabs models have been used in calculations. The first set corresponds to the results represented in Figure S8. In this case a graphene sheet with $\mathrm{Nx}=7$ and $\mathrm{Ny}=3$ periodic units having lateral dimensions of $12.788 \times 17.227 \AA^{2}$ has been used. As shown previously, ${ }^{\mathrm{S} 6}$ such a supercell can accommodate a periodic repeating carbon nitride layer adsorbed on a graphene sheet. For this model a $\mathrm{Cu}$ nanoparticle, represented either by a small $\mathrm{Cu}_{19}$ cluster (panels a-f) or a periodic $\mathrm{Cu}_{36}$ nanowire (panels g-i) running along Oy axis, were adsorbed on the graphene sheet at a $\mathrm{C}-\mathrm{C}$ defect functionalized with a mixture of $\mathrm{COOH}, \mathrm{O}$ and $\mathrm{H}$ species. A vacuum layer of about $14.1 \AA$ has been used to minimize the lateral interaction among adjacent cells. For the second model, corresponding to results represented in Figure 5 in the main text, the supercell has been doubled along Ox axis to accommodate two independent carbon nitride chains (that can be seen as a top view in panels c) and d) of Figure 5) adsorbed near a $\mathrm{Cu}_{50}$ nanorod. This 
nanorod is periodic along the Oy axis of the slab and contains three atomic layers, initially extracted from a regular $\mathrm{Cu}(111)$ surface. In all optimization cases sampling of the Brillouin zone was done using the Monkhorst-Pack scheme ${ }^{\mathrm{S} 7}$ with a $0.03 \AA^{-1} \mathrm{k}$-point mesh, which was decreased to $0.02 \AA^{-1}$ for electronic properties analysis. The amount of charge transfer among different subsystems has been determined using the Bader charges ${ }^{\mathrm{S} 8}$ obtained using the charge density decomposition algorithm introduced by Henkelman et al. ${ }^{\mathrm{S}}$ 
a)

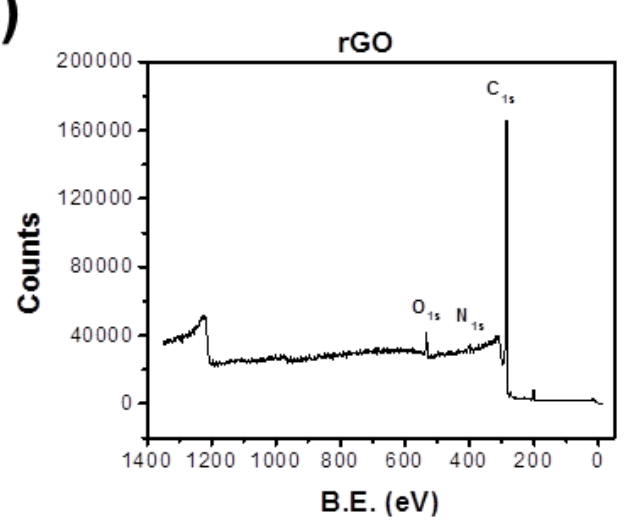

c)

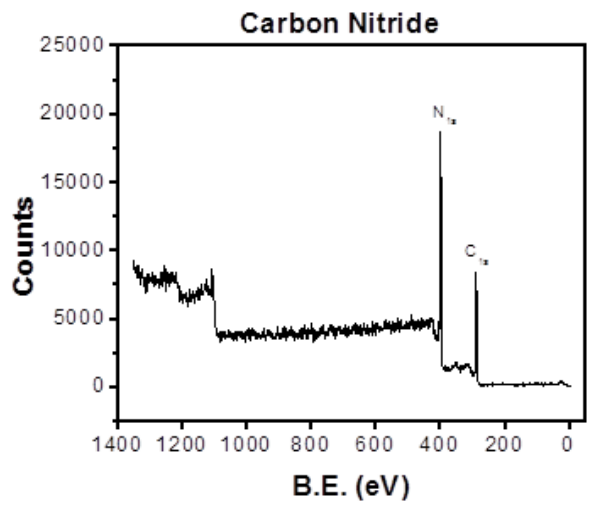

b)

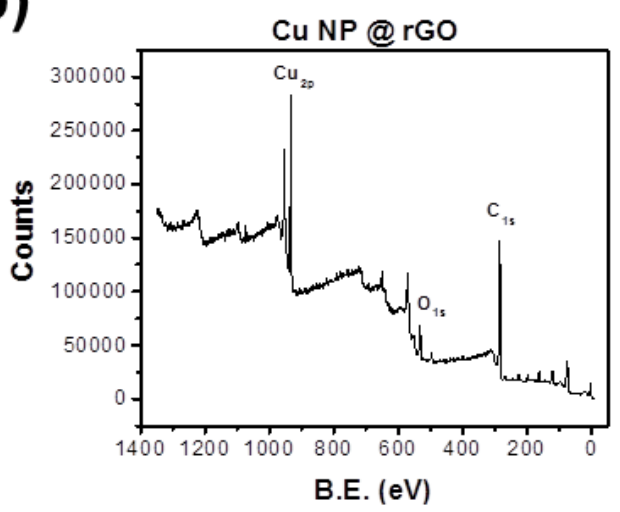

d)

\begin{tabular}{|c|c|c|c|c|}
\hline Sample & $\begin{array}{c}\mathrm{C} \\
\text { atom\% }\end{array}$ & $\begin{array}{c}\mathrm{O} \\
\text { atom\% }\end{array}$ & $\begin{array}{c}\mathrm{N} \\
\text { atom\% }\end{array}$ & $\begin{array}{c}\mathrm{Cu} \\
\text { atom\% }\end{array}$ \\
\hline rGO & 94.1 & 4.7 & 1.2 & -- \\
\hline $\begin{array}{c}\text { CuNP } \\
\text { @rGO }\end{array}$ & 81.2 & 9.2 & -- & 9.6 \\
\hline $\begin{array}{c}\text { Carbon } \\
\text { nitride }\end{array}$ & 40.9 & -- & 59.1 & - \\
\hline
\end{tabular}

Figure S1. Survey XPS of a) rGO, b) CuNP@rGO, and c) carbon nitride; d) elemental content at the surface of each material as determined by survey XPS. 

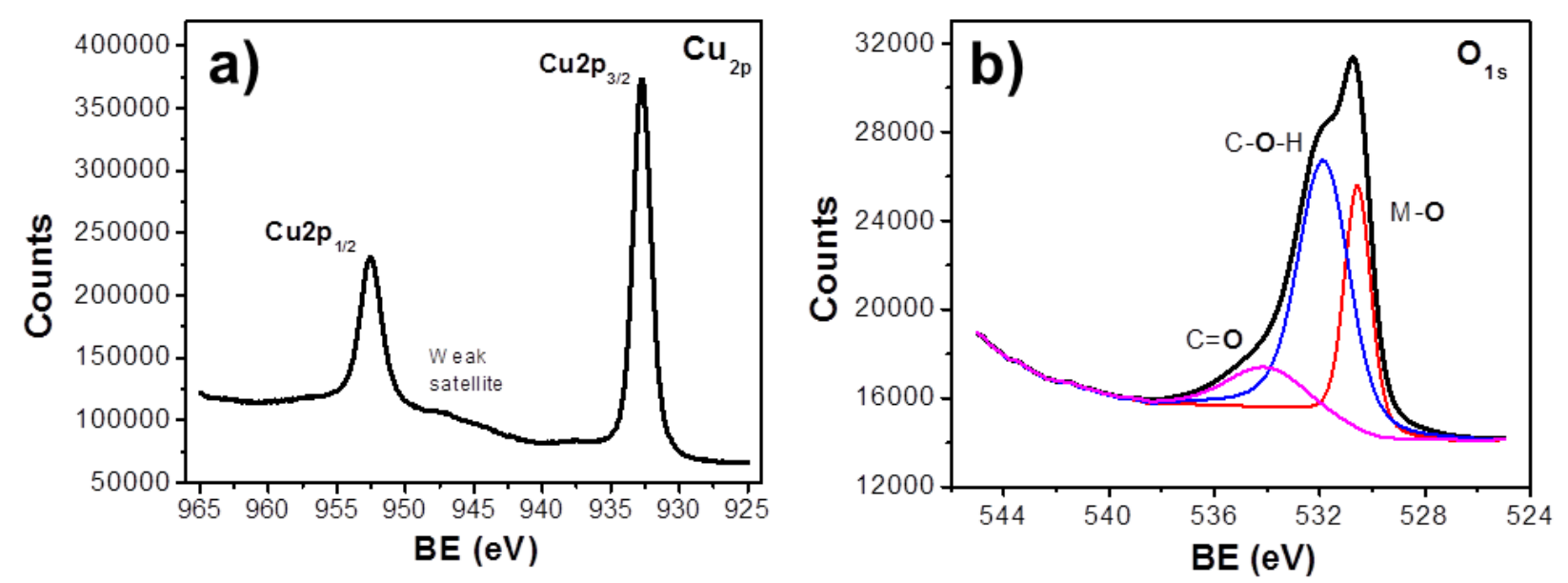

Figure S2. High-resolution a) $\mathrm{Cu}_{2 \mathrm{p}}$ and b) $\mathrm{O}_{1 \mathrm{~s}}$ XPS scans of CuNP@rGO. 


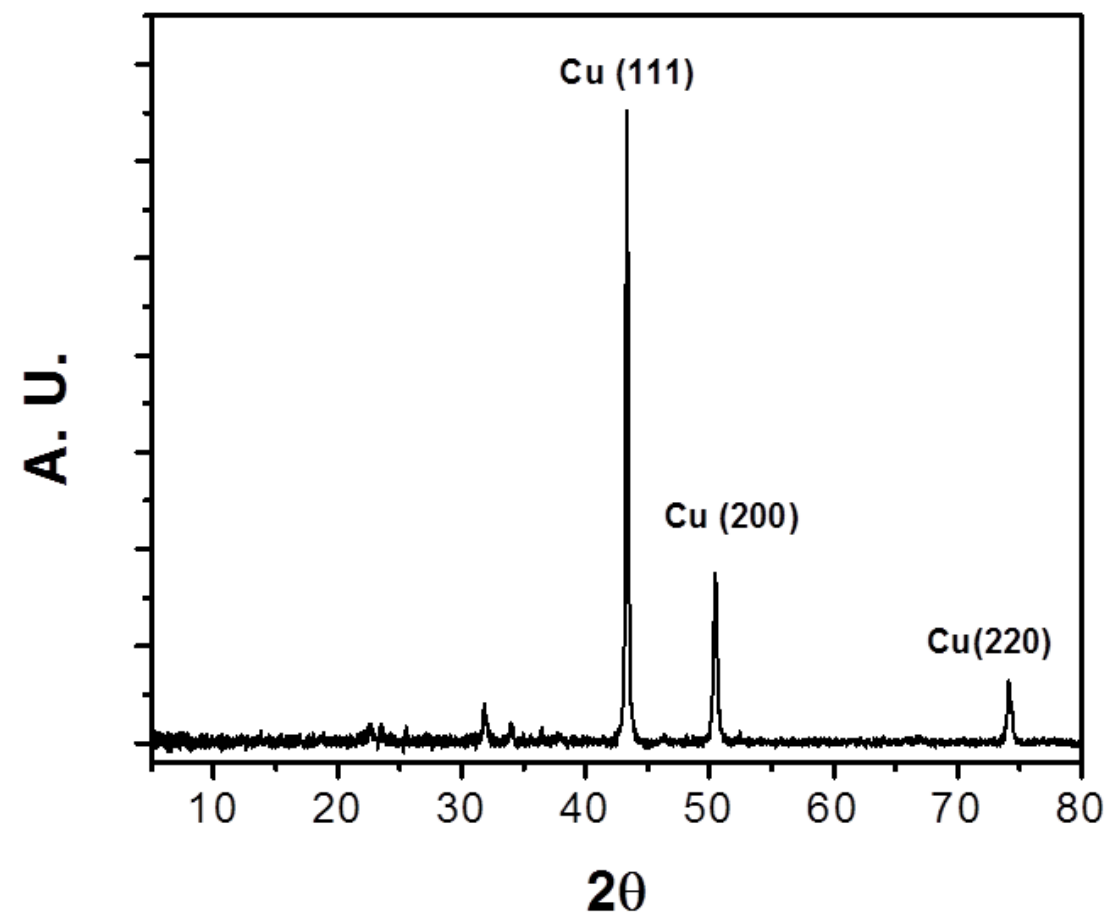

Figure S3. PXRD of CuNP@rGO. The peaks identified correspond to $\mathrm{Cu}(111), \mathrm{Cu}(200)$ and $\mathrm{Cu}(220)$ lattice planes. 


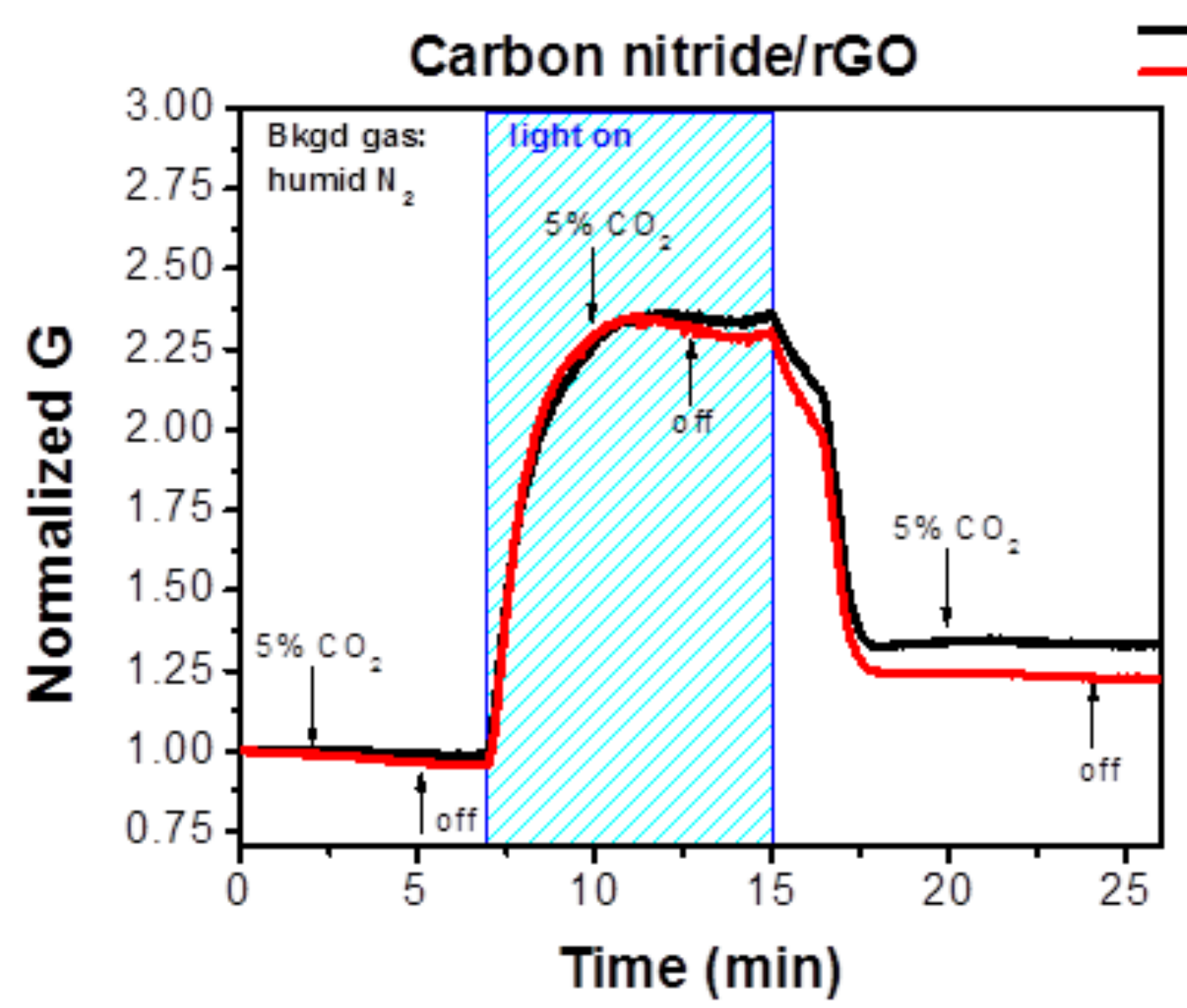

Figure S4. Response of carbon nitride/rGO (no $\mathrm{Cu}$ NPs) chemiresistor toward 5 vol\% $\mathrm{CO}_{2}$ (background gas: humid $\mathrm{N}_{2}$ ). Reproduced with permission from reference S6. Copyright 2017 The American Chemical Society. 

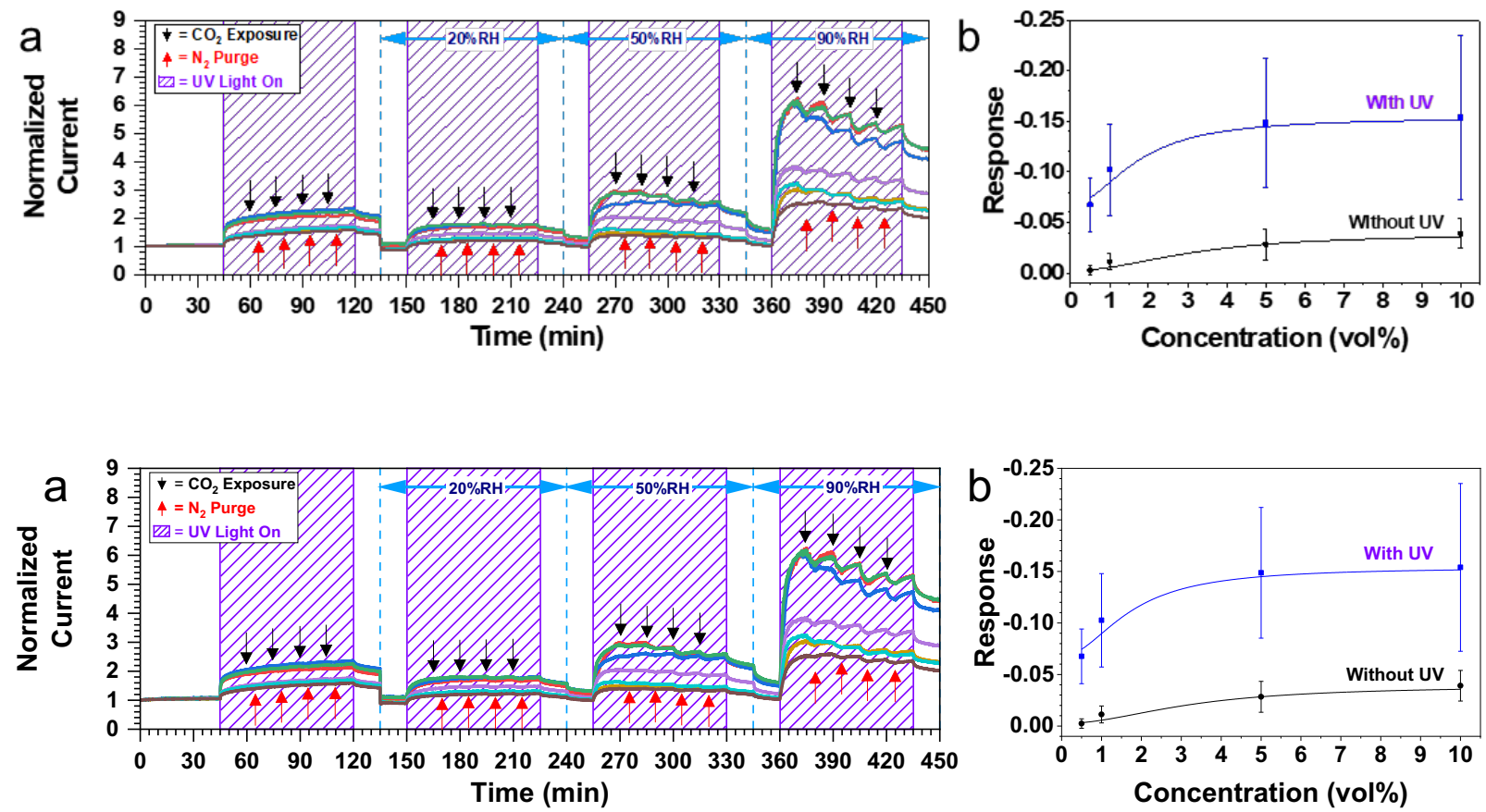

Figure S5. Device variability results. (a) The $\mathrm{CO}_{2}$ sensing traces for 7 devices. (b) The average and standard deviation of the responses of the 7 devices with and without UV. The large error bars are due to the heterogeneity of the material. 

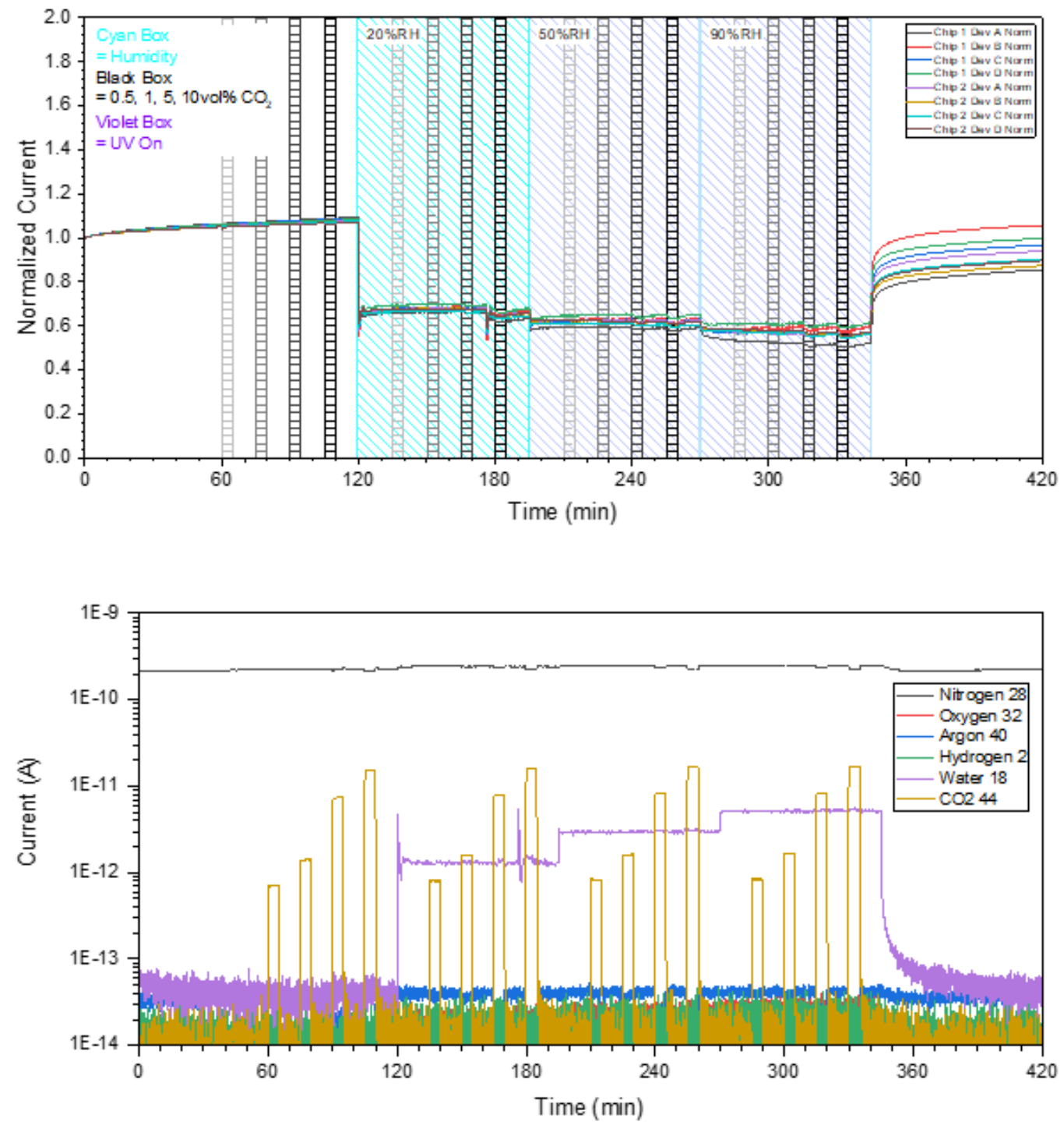

Figure S6. Response of carbon nitride/CuNP@rGO chemiresistor toward $\mathrm{CO}_{2}$ without UV light irradiation in various humidities. 

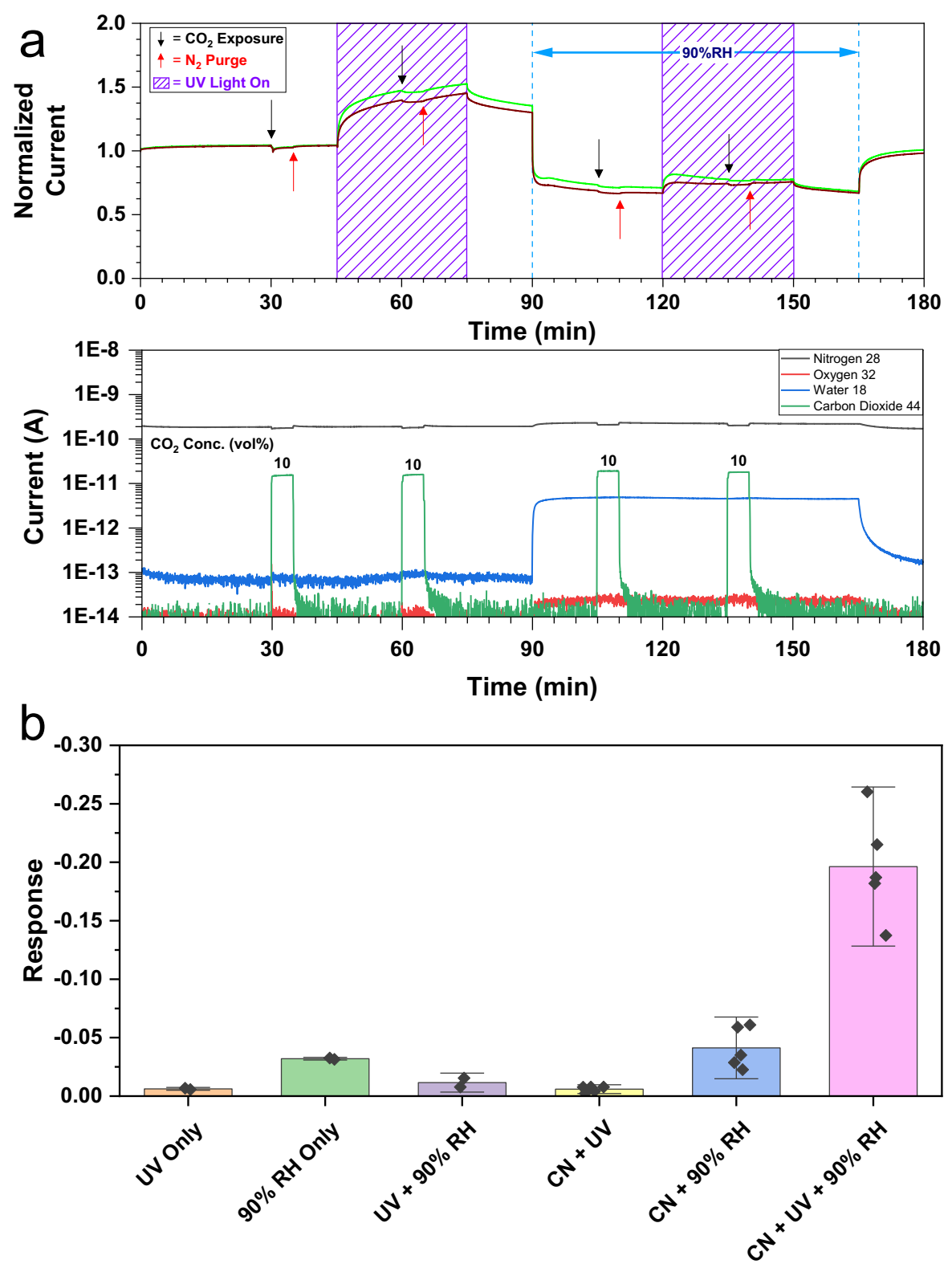

Figure S7. $\mathrm{CO}_{2}$ sensitivity of CuNP-rGO (no carbon nitride). (a) CuNP-rGO chemiresistor response to $10 \mathrm{vol} \% \mathrm{CO}_{2}$ gas exposures in $\mathrm{N}_{2}$ background with $90 \% \mathrm{RH}$ and light irradiation. Gas stream is monitored using on-line mass spectrometry. (b) $\mathrm{CO}_{2}$ sensitivity comparison of the CuNP-rGO chemiresistor with and without carbon nitride (CN). 


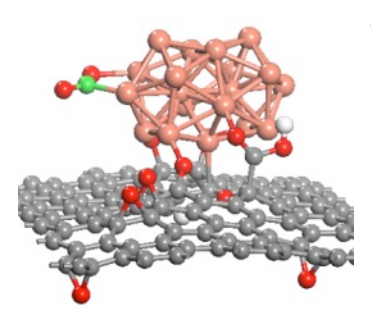

$E_{a d s}=6.9 \mathrm{kcal} / \mathrm{mol}$

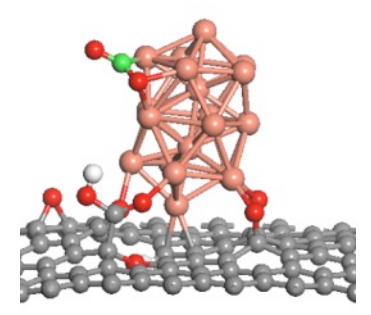

$E_{a d s}=7.3 \mathrm{kcal} / \mathrm{mol}$ a)

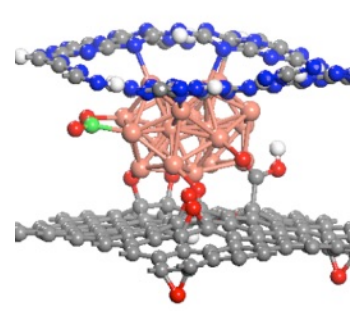

$E_{a d s}=12.3 \mathrm{kcal} / \mathrm{mol}$

d)

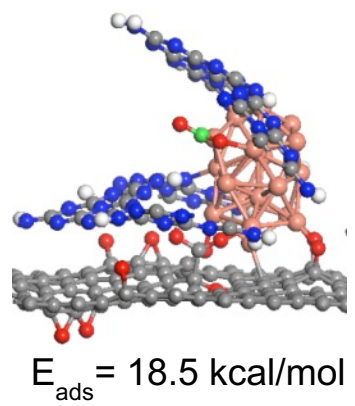

g)

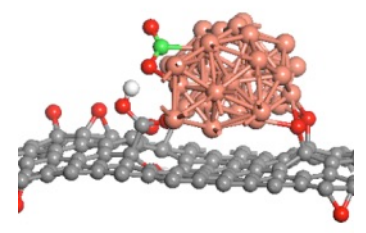

$E_{a d s}=8.0 \mathrm{kcal} / \mathrm{mol}$

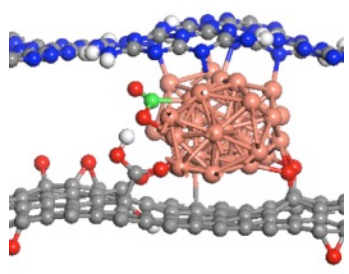

$E_{a d s}=10.7 \mathrm{kcal} / \mathrm{mol}$ b)
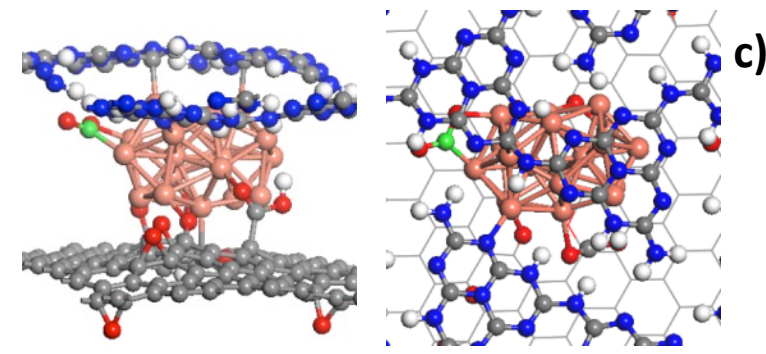

$E_{\text {ads }}=17.4 \mathrm{kcal} / \mathrm{mol}$

e)
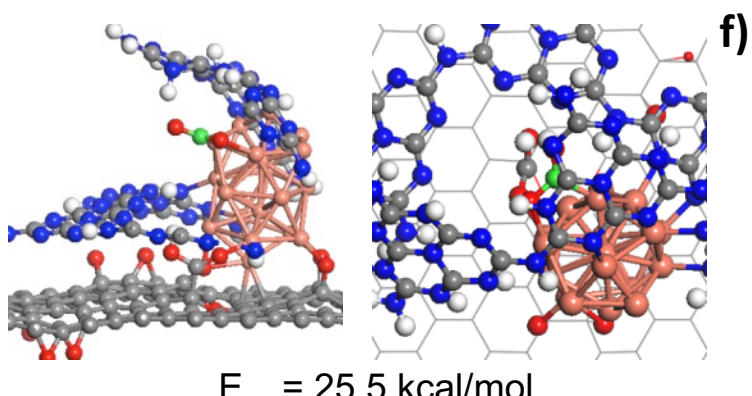

$E_{a d s}=25.5 \mathrm{kcal} / \mathrm{mol}$

h)

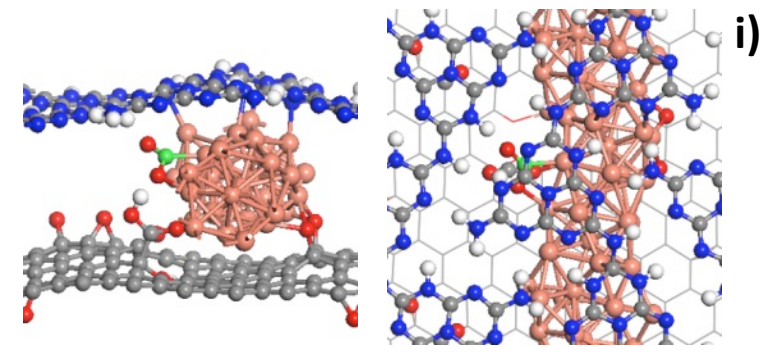

$E_{a d s}=21.3 \mathrm{kcal} / \mathrm{mol}$

Figure S8. Variation of the adsorption energies of $\mathrm{CO}_{2}$ on $\mathrm{Cu}$ cluster and $\mathrm{Cu}$ nanowire supported on a rGO sheet and in the presence of a carbon nitride layer decorated with different amounts of hydrogenated pyridinic atoms. The $\mathrm{Cu}_{19}$ cluster was taken to adsorb in a laying down configuration (panels a-c) or vertically (panels d-f) on rGO at a functionalized $\mathrm{C}-\mathrm{C}$ defect. The $\mathrm{Cu}_{36}$ nanowire (panels $\mathrm{g}-\mathrm{i}$ ) is also adsorbed near a functionalized defect and extends periodically along the Oy axis of the supercell. In all cases the $\mathrm{C}-\mathrm{C}$ defect of $\mathrm{rGO}$ was functionalized with a mixture of $\mathrm{COOH}, \mathrm{O}$ and $\mathrm{H}$ species. In panels c), f) and i) in addition to the side view, a top view panel is included. In these cases the carbon nitride layer contains six additional $\mathrm{H}$ species, relative to the corresponding structures depicted in panels b), e) and $h$ ) where none of the pyridinic $\mathrm{N}$ are hydrogenated. In panel a-c) and g-i) the carbon nitride layer is adsorbed on the $\mathrm{Cu}$ cluster/nanowire while in panels d-f) the carbon nitride layer is adsorbed both above and laterally near the $\mathrm{Cu}$ cluster. For each configuration the indicated adsorption energy corresponds to that of $\mathrm{CO}_{2}$ molecule. The $\mathrm{C}$ atoms are indicated in gray excepting the $\mathrm{C}$ atom of $\mathrm{CO}_{2}$ which is shown in green, $\mathrm{N}$ atoms in blue, $\mathrm{O}$ atoms in red, $\mathrm{H}$ atoms in white and $\mathrm{Cu}$ atoms in brown. 


\section{Supporting Information References}

S1 Kresse, G.; Furthmüller, J., Efficiency of Ab-Initio Total Energy Calculations for Metals and Semiconductors Using a Plane-Wave Basis Set. Comput. Mater. Sci. 1996, 6, 15-50.

S2 Kresse, G.; Furthmüller, J., Efficient Iterative Schemes for Ab Initio Total-Energy Calculations Using a Plane-Wave Basis Set. Phys. Rev. B 1996, 54, 11169-11186.

S3 Perdew, J. P.; Burke, K.; Ernzerhof, M., Generalized Gradient Approximation Made Simple. Phys. Rev. Lett. 1996, 77, 3865-3868.

S4 Blöchl, P. E., Projector Augmented-Wave Method. Phys. Rev. B 1994, 50, 17953-17979.

S5 Grimme, S.; Antony, J.; Ehrlich, S.; Krieg, H., A Consistent and Accurate Ab Initio Parametrization of Density Functional Dispersion Correction (DFT-D) for the 94 elements H-Pu. J. Chem. Phys. 2010, 132, 154104.

S6 Ellis, J.E.; Sorescu, D. C.; Burkert, S. C.; White, D. L.;Star, A. "Uncondensed Graphitic Carbon Nitride on Reduced Graphene Oxide for Oxygen Sensing via a Photoredox Mechanism" ACS Appl. Mater. Interfaces 2017, 9, 27142-27151.

S7 Monkhorst, H. J.; Pack, J. D., Special Points for Brillouin-Zone Integrations. Phys. Rev. B 1976, 13, 5188-5192.

S8 Bader, R. F. W., Atoms in Molecules: A Quantum Theory. Oxford University Press: New York, 1994.

S9 Sanville, E.; Kenny, S. D.; Smith, R.; Henkelman, G., Improved Grid-Based Algorithm for Bader Charge Allocation. J. Comput. Chem. 2007, 28, 899-908. 